\title{
Changes in executive function and gait in people with mild cognitive impairment and Alzheimer disease
}

\author{
Natália Oiring de Castro Cezar ${ }^{\oplus}$, Juliana Hotta Ansai ${ }^{\odot}{ }^{\oplus}$, Marcos Paulo Braz de Oliveira ${ }^{1 \odot}$, \\ Danielle Chagas Pereira da Silva ${ }^{1}$, Francisco Assis Carvalho Vale ${ }^{3}$, \\ Anielle Cristhine de Medeiros Takahashi ${ }^{\oplus}$, Larissa Pires de Andrade ${ }^{1 \odot}$
}

\begin{abstract}
Changes in executive function and motor aspects can compromise the prognosis of older adults with mild cognitive impairment (MCI) and favor the evolution to dementia. Objectives: The aim of this study was to investigate the changes in executive function and gait and to determine the association between changes in these variables. Methods: A 32-month longitudinal study was conducted with 40 volunteers: 19 with preserved cognition $(\mathrm{PrC}), 15$ with $\mathrm{MCl}$ and 6 with Alzheimer disease (AD). Executive function and gait speed were assessed using the Frontal Assessment Battery, the Clock-Drawing test and the 10-meter walk test. For data analysis, the Pearson product-moment correlation, two-way repeated-measures ANOVA, and chi-square were conducted. Results: After 32 months, an improvement in the executive function was found in all groups ( $p=0.003)$. At baseline, gait speed was slower in individuals with $\mathrm{MCl}$ and $\mathrm{AD}$ compared to those with $\operatorname{PrC}(\mathrm{p}=0.044)$, that was maintained after the follow-up $(p=0.001)$. There was significant increase in number of steps in all groups $(p=0.001)$. No significant association was found between changes in gait speed and executive function. Conclusion: It should be taken into account that gait deteriorates prior to executive function to plan interventions and health strategies for this population.
\end{abstract}

Keywords: walking speed, longitudinal studies, cognition, cognitive dysfunction, aging.

ALTERAÇÕES NA FUNÇÃO EXECUTIVA E NA MARCHA EM PESSOAS COM COMPROMETIMENTO COGNITIVO LEVE E DOENÇA DE ALZHEIMER

RESUMO. Alterações na função executiva e nos aspectos motores podem comprometer o prognóstico de idosos com comprometimento cognitivo leve (CCL) e favorecer a evolução para demência. Objetivos: 0 objetivo deste estudo foi investigar alterações na função executiva e na marcha e determinar a associação entre alterações nessas variáveis. Métodos: Foi realizado um estudo longitudinal de 32 meses com 40 voluntários: 19 com cognição preservada (PrC), 15 com CCL e 6 com doença de Alzheimer (DA). A função executiva e a velocidade da marcha foram avaliadas por meio de bateria de avaliação frontal, do teste de desenho do relógio e do teste de caminhada de 10 metros. Para a análise de dados, o coeficiente de correlação produto-momento de Pearson, ANOVA de medidas repetidas bidirecional e o qui-quadrado foram realizados. Resultados: Após 32 meses, houve melhora na função executiva em todos os grupos $(p=0,003)$. No início do estudo, a velocidade da marcha foi mais lenta nos indivíduos com CCL e DA em comparação com os $\operatorname{PrC}(p=0,044)$, que foi mantida após o acompanhamento $(p=0,001)$. Houve aumento significativo no número de etapas em todos os grupos $(p=0,001)$. Não foi encontrada associação significativa entre alterações na velocidade da marcha e função executiva. Conclusão: Deve-se levar em consideração que a marcha se deteriora antes da função executiva para planejar intervenções e estratégias de saúde para essa população.

Palavras-chave: velocidade de caminhada, estudos Iongitudinais, cognição, disfunção cognitiva, envelhecimento.

\footnotetext{
This study was conducted at the Department of Physical Therapy, Universidade Federal de São Carlos, São Carlos, SP, Brazil.

'Department of Physical Therapy, Universidade Federal de São Carlos - São Carlos, SP, Brazil.

${ }^{2}$ Graduate Program in Movement Sciences, Universidade Federal de Mato Grosso do Sul - Campo Grande, MS, Brazil.

${ }^{3}$ Departament of Medicine, Universidade Federal de São Carlos - São Carlos, SP, Brazil.
}

Larissa Pires de Andrade. Physiotherapy Department, Universidade Federal de São Carlos, Rodovia Washington Luis, Km 235 - Monjolinho - 13565-905 São Carlos SP - Brazil. E-mail: larissa.andrade@ufscar.br

Funding: National Council for Scientific and Technological Development (CNPq) - process number 426666 / 2016-0; Coordination for the Improvement of Higher Education Personnel (CAPES) - Finance Code 001; Amparo Foundation Research of the State of São Paulo (FAPESP).

Disclosure: The authors report no conflicts of interest.

Received on April 15, 2020. Accepted in final form on December 16, 2020.

\section{(cc) BY}




\section{INTRODUCTION}

Older adults with mild cognitive impairment (MCI) and Alzheimer disease $(\mathrm{AD})$ experience changes in executive function (EF), ${ }^{1,2}$ which are more pronounced in the latter group. ${ }^{3} \mathrm{EF}$ is a broad term related to planning, working memory, cognitive flexibility, monitoring, decision-making, and the ability to solve novel problems. ${ }^{4}$

A study that monitored older adults with preserved cognition $(\operatorname{PrC}), \mathrm{MCI}$, and mild to moderate $\mathrm{AD}$ for three years found that EF scores were significantly worse in those with $\mathrm{AD}$ compared to those with $\mathrm{MCI}$, who, in turn, had worse scores than those with $\operatorname{PrC} .{ }^{5}$ Considering the heterogeneous sample of the $\mathrm{AD}$ group (patients in the mild and moderate phases), studies assessing only older adults with mild $\mathrm{AD}$ are needed, since this population differs greatly from the population in the moderate phase of the disease with regard to cognitive and motor aspects. ${ }^{6-8}$

A relationship has been found between changes in gait and EF in older adults with cognitive impairment ${ }^{9,10}$ and those with $\mathrm{AD}$ in the mild and moderate phases. ${ }^{6} \mathrm{~A}$ poorer performance regarding $\mathrm{EF}$ measures is associated with a shorter step length and width as well as slower gait. ${ }^{11}$ In a study with a 23-month follow-up, reductions in cadence (number of steps per minute) and gait speed (GS) were associated with global cognitive decline and diminished EF in older adults with $\operatorname{PrC} .{ }^{12}$

Slow GS is a strong predictor of dementia. ${ }^{13}$ Older adults with MCI who have lower limb impairment are more likely to develop $\mathrm{AD}$ than those with $\mathrm{MCI}$ and preserved lower limb function. ${ }^{14}$ Moreover, GS is a potential marker for the early identification of MCI. ${ }^{15,16}$

Few longitudinal studies have analyzed the relationship between gait and EF in older adults with and without cognitive impairment or have performed comparative analyses of older adults with $\operatorname{PrC}, \mathrm{MCI}$, and mild AD. As early diagnosis is important to the prognosis of older adults with $\mathrm{MCI}$ and its progression to dementia, the present study was conducted to identify changes in motor aspects and EF in this population and determine which ones declines first. The prompt identification of cognitive and gait changes enables the establishment of preventive actions. Therefore, the results of the present longitudinal analytical study can contribute to the planning of future interventions to mitigate such changes and their consequences.

Therefore, the aim of the present study was to investigate changes in $\mathrm{EF}$ and gait in older adults with $\operatorname{PrC}, \mathrm{MCI}$, and mild AD over a 32-month period and to analyze the correlation between the changes in these two variables. The hypothesis was that those with greater cognitive impairment would demonstrate a greater worsening in EF and GS after 32 months. It was also believed that the 10-meter walk test would be strongly correlated with EF tests.

\section{METHODS}

The present longitudinal analytical study was conducted with data from the "Brazilian longitudinal study about motor alterations in older adults with cognitive disorders". This study received approval from the local Human Research Ethics Committee (certificate number: 72774317.7.0000.5504). All volunteers signed a statement of informed consent.

\section{Sample}

The subjects were recruited through leaflets, posters, and local radio and television channels. In addition, older people attending the Center for Medical Specialties, Universidade Aberta da Terceira Idade (São Carlos - SP), and School Health Unit (Universidade Federal de São Carlos) were contacted. This is a convenience sample.

Community-dwelling adults aged 65 years old or older who could be contacted by telephone or at their residential address were eligible for the study. Inclusion criteria included ability to walk at least $12.4 \mathrm{~m}$ with or without the aid of gait-assistance device, availability to participate in the evaluations, and admission to one of the three groups: $\operatorname{PrC}, \mathrm{MCI}$ or mild AD. Exclusion criteria were: other neurological diseases that interfered in cognition or mobility and associated medications(such as motor alterations after stroke, Parkinson disease, multiple sclerosis, Huntington disease, epilepsy, traumatic brain injury, and advanced or moderate-stage of dementia), and severe uncorrected audiovisual impairment that would hinder test performance. Moreover, after the 32-month follow-up, participants with unsuccessful telephone or residential contact, those who died, became wheelchair-bound or bedridden, were unable to continue in the study due to illness (i.e., influenza, deep vein thrombosis, acute lumbosacral pain, etc.), those who moved to a different city, and those not interested in continuing the evaluations were also excluded from the study. The massive loss of the initial sample may have caused a significant bias in the research. This type of loss is commonly observed in longitudinal studies with this population. We sought to reduce losses by offering transportation to participants, telephone contact with participants during the period between assessments, obtaining contact information from family or friends in case of a change of address or telephone number. Three attempts were made when trying to contact participants before they were considered a dropout. 
The diagnosis and phase of $\mathrm{AD}$ was confirmed by a single neurologist trained in the field of behavioral neurology, based on the National Institute on Aging and Alzheimer's Association criteria. ${ }^{17}$ Only individuals with a score of 1 on the Clinical Dementia Rating (CDR) scale were included in the mild AD group. ${ }^{18}$ Participants classified as $\operatorname{PrC}$ obtained a normal score on the Mini-Mental State Examination (MMSE) ${ }^{19}$ and did not meet the criteria for $\mathrm{MCI}$ or dementia. For the diagnosis of MCI: cognitive complaint manifested by the participant or a caregiver (person who cares for the older adult for at least $12 \mathrm{~h}$ per day, four times a week); objective cognitive decline with a score of 0.5 on the $\mathrm{CDR} ;{ }^{18}$ normal general cognitive function for level of schooling assessed by the MMSE $;^{19}$ and preserved functioning evaluated by the Pfeffer Scale. ${ }^{20,21}$ After 32 months, the participants were reclassified.

\section{Evaluations}

Evaluations were performed on two occasions: baseline and follow-up (Figure 1). As there are studies research with shorter ${ }^{22}$ and intermediate ${ }^{12,23}$ follow-up, this study approached the longer period of 32 months. Participants were evaluated in the laboratory wearing comfortable clothes, closed-toe shoes, hearing aid and/ or glasses, and no physical activity in the previous 24 hours. The tests were administered in a closed environment with a flat floor and minimal external visual and auditory stimuli. Evaluators were properly trained and explained all the tests to the participants in a simple, objective, and standardized way. When necessary, the participants had the help of a caregiver for the recording of the patient's history (socio-demographic and health characteristics, such as age, gender, body mass index, schooling, use of medications in general

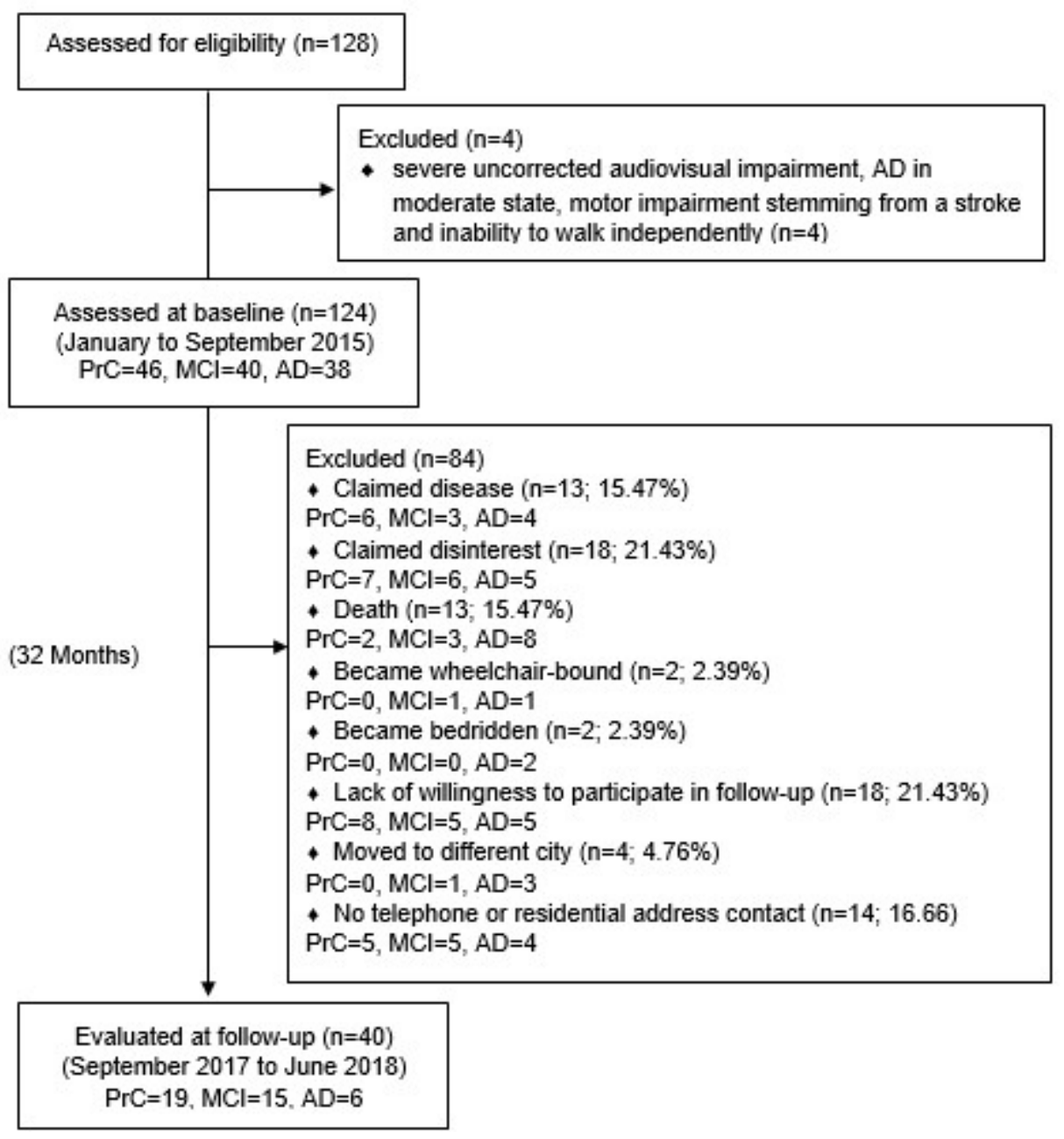

PrC: preserved cognition; MCl: mild cognitive impairment; AD: Alzheimer disease.

Figure 1. Sample flowchart. 
and psychotropic drugs, and presence of disease in general, depression, and anxiety) and for the screening of depressive symptoms. ${ }^{24}$

The assessment of the EF was performed using the Frontal Assessment Battery (FAB) and clock-drawing test (CDT). The FAB is employed to evaluate frontal cognitive function, including EF. The maximum score is $18 .^{25,26}$ Its inter-rater reliability is 0.87 and discriminant validity is $89.1 \%{ }^{25}$ The CDT is used to assess EF based on the design of an analog clock, for which the maximum score is 10 . Its inter-rater reliability is $0.86 .{ }^{27} \mathrm{CDT}$ has been translated, adapted, and validated for use in older adults in Brazil. ${ }^{28}$ In addition, CDT has good inter-examiner and test-retest reliability, high sensitivity and specificity, concurrent validity and predictive validity. ${ }^{29}$ The FAB and CDT were chosen because these tests detect changes in EF and are fast and easy to administer. Moreover, a strong association has been reported between frontal function and kinetic gait variables. ${ }^{6}$

GS was determined using the 10 -meter walk test (10mWT) by video and stopwatch. On the $10 \mathrm{mWT}$, participants are instructed to walk $12.4 \mathrm{~m}$ in a flat corridor at their usual pace. The initial and final $1.2 \mathrm{~m}$ are discarded to eliminate the components of acceleration and deceleration. ${ }^{30}$ The test was performed only once. The elements analyzed were the number of steps, GS, and cadence. Walk tests ranging from six to $15 \mathrm{~m}$ have good reliability and reproducibility and are valid for assessing physical mobility in a clinical or home setting. ${ }^{30}$ Inter-rater reliability for the walk test is $0.985 .{ }^{31}$ The $10 \mathrm{mWT}$ was chosen because it is widely used in the literature for the evaluation of GS. The minimal detectable change with $90 \%$ confidence for GS is $0.21 \mathrm{~m} / \mathrm{s}^{32}$

\section{Data analysis}

Statistical tests were performed using the SPSS software, with a significance level of $\alpha=0.05$. The Kolmogorov-Smirnov test was used to determine the normality of data distribution. One-way analysis of variance and the chi-square test were used to determine differences among the groups regarding the initial clinical and sociodemographic characteristics. When an overall group difference was significant, a post hoc independent Student's t-test was performed.

Two-way repeated-measures ANOVA was used to determine the interaction between group and time with regard to EF and performance on the $10 \mathrm{mWT}$. When a significant interaction was identified, analyses of the main simple effects were performed. Pearson's correlation test was used to determine the correlation between the change in EF and GS between evaluations.

\section{RESULTS}

One hundred and twenty-four volunteers were evaluated at baseline: 46 with $\operatorname{PrC}, 40$ with $\mathrm{MCI}$, and 38 with mild AD. After a 32-month follow-up, the dropout rate was $67.74 \%(\mathrm{n}=84)$ due to deaths $(15.47 \%)$, lack of willingness to participate in the follow-up evaluation $(21.43 \%)$, change of address to a different city (4.76\%), having become bedridden (2.39\%), having become wheelchair-bound (2.39\%), claimed disease (15.47\%), disinterest (21.43\%), and loss of contact via telephone or residence $(16.66 \%)$. Thus, the final sample was composed of 19 older adults with $\operatorname{PrC}$, 15 with $\mathrm{MCI}$, and six with $\mathrm{AD}$ (Figure 1). There was a progression of two $\operatorname{PrC}$ participants to $\mathrm{MCI}$ and three $\mathrm{MCI}$ to DA, as well as a regression of six $\mathrm{MCI}$ to $\operatorname{PrC}$ after a 32-month follow-up.

Regarding sociodemographic characteristics at baseline, significant differences among the groups were found only for gender, total number of medications, and diseases. The $\mathrm{MCI}$ group had a higher number of women (93.3\%) in comparison to the other groups. The MCI and mild $\mathrm{AD}$ groups took more medications and had more diseases compared to the $\operatorname{PrC}$ group (Table 1 ).

In the intragroup analysis of the change in GS on the $10 \mathrm{mWT}$ over time, a significant group versus time interaction was found $(p=0.019)$. In the analysis of the main simple effects, both the $\operatorname{PrC}$ and mild AD groups had a worse performance after 32 months compared to baseline. A significant difference was found between the PrC and MCI groups at baseline $(\mathrm{p}=0.024)$, with a worse performance in the MCI group. Regarding the number of steps required to complete the $10 \mathrm{mWT}$, no significant group versus time interaction was found, but a significant increase in the number of steps was found at follow-up in all groups ( $\mathrm{p}=0.001$ ) (Table 2).

Regarding the frontal functions, the analysis of the $\mathrm{FAB}$ results revealed no significant group versus time interaction. Improvements in $\mathrm{FAB}$ scores were found at follow-up in all groups $(\mathrm{p}=0.003)$. Moreover, significant differences were found between the $\mathrm{PrC}$ and MCI groups and between the $\operatorname{PrC}$ and mild $\mathrm{AD}$ groups at both evaluation times $(\mathrm{p}=0.006)$. No significant group versus time interaction was found with regard to cadence on the $10 \mathrm{mWT}$ or the CDT and no main significant group-time effect was found in these analyses (Table 2).

No significant correlation was found between the change in EF (FAB) and change of GS in any of the groups. A correlation was found between the change in the $\mathrm{FAB}$ and the number of steps in the mild $\mathrm{AD}$ group and between the change in the FAB and cadence in the PrC group (Table 3 ). 


\section{DISCUSSION}

In the present study, 32 months was not enough time for EF impairment in older adults with $\operatorname{PrC}, \mathrm{MCI}$, and mild AD. However, a decrease in GS at follow-up was found in those with $\operatorname{PrC}$ and mild AD. The findings suggest that the slowing of gait in individuals with $\operatorname{PrC}$ and mild $\mathrm{AD}$ is due to aging and cognitive impairment, respectively.

The deceleration in GS over time has been described in previous studies ${ }^{33}$ and GS has been associated with cognitive impairment. ${ }^{13}$ These findings are in agreement with Ojagbemi et al., ${ }^{23}$

Table 1. Descriptive characteristics of the sample.

\begin{tabular}{|c|c|c|c|c|}
\hline $\begin{array}{l}\text { Characteristics } \\
(\mathrm{M} \pm \mathrm{SD})\end{array}$ & $\begin{array}{l}\text { PrC group } \\
(n=19)\end{array}$ & $\begin{array}{l}\text { MCI group } \\
(n=15)\end{array}$ & $\begin{array}{l}\text { AD group } \\
\qquad(n=6)\end{array}$ & p-value \\
\hline Age (years) & $72.7 \pm 6.7$ & $72.8 \pm 5.4$ & $77.6 \pm 4.1$ & 0.195 \\
\hline Female gender, n (\%) & $10(52.6)$ & $14(93.3)$ & $3(50.0)$ & $0.026^{\star}$ \\
\hline Body mass index $\left(\mathrm{kg} / \mathrm{m}^{2}\right)$ & $28.5 \pm 5.7$ & $29.8 \pm 3.9$ & $26.1 \pm 4.0$ & 0.296 \\
\hline Schooling (years) & $7.9 \pm 4.2$ & $5.2 \pm 3.9$ & $6.5 \pm 5.0$ & 0.207 \\
\hline Total number of medications & $2.0 \pm 1.5$ & $5.5 \pm 3.1^{\#}$ & $5.5 \pm 2.9^{\#}$ & $<0.001^{*}$ \\
\hline Use of psychotropics, n (\%) & $1(5.3)$ & $5(33.3)$ & $5(83.3)$ & $<0.001^{*}$ \\
\hline Total number of diseases & $1.7 \pm 1.3$ & $3.1 \pm 1.4^{\#}$ & $3.8 \pm 1.3^{\#}$ & $0.003^{\star}$ \\
\hline Diagnosis of depression, $\mathrm{n}(\%)$ & $0(0)$ & $0(0)$ & $0(0)$ & - \\
\hline Diagnosis of anxiety, n (\%) & $1(5.3)$ & $1(6.7)$ & $0(0)$ & 0.816 \\
\hline GDS (0-15) & $1.8 \pm 1.6$ & $3.5 \pm 2.4$ & $2.8 \pm 1.8$ & 0.057 \\
\hline
\end{tabular}

$\mathrm{M} \pm \mathrm{SD}$ : mean \pm standard deviation; $\mathrm{n}(\%)$ : number of individuals (percentage); PrC: preserved cognition; $\mathrm{MCl}$ : mild cognitive impairment; $\mathrm{AD}$ : Alzheimer disease; $\mathrm{kg} / \mathrm{m}^{2}: \mathrm{kilogram} / \mathrm{square}$ meter; GDS: Geriatric Depression Scale; $>5$ points is suggestive of depression; $\geq 10$ points is almost always indicative of depression; $>5$ points should warrant follow-up comprehensive assessment; ${ }^{*} \mathrm{p}<0.05$ between groups; $\# p<0.05$ in comparison to $\operatorname{PrC}$ Group.

Table 2. Performance on 10-meter walk test, Frontal Assessment Battery and clock-drawing test tests in older adults with preserved cognition, mild cognitive impairment and mild Alzheimer disease over 32 months $(n=40)$.

\begin{tabular}{|c|c|c|c|c|c|c|c|c|c|c|}
\hline \multirow{2}{*}{$\begin{array}{l}\text { Characteristics } \\
(\mathrm{M} \pm \mathrm{SD})\end{array}$} & \multicolumn{2}{|c|}{$\begin{array}{l}\text { PrC group } \\
(n=19)\end{array}$} & \multicolumn{2}{|c|}{$\begin{array}{l}\text { MCI group } \\
\quad(n=15)\end{array}$} & \multicolumn{2}{|c|}{$\begin{array}{l}\text { AD group } \\
(n=6)\end{array}$} & \multirow{2}{*}{$\begin{array}{c}\text { Time-group } \\
\text { interaction } \\
\text { p-value* }\end{array}$} & \multirow{2}{*}{$\begin{array}{c}\text { Time-group } \\
\text { interaction } \\
\text { Power* }\end{array}$} & \multirow{2}{*}{$\begin{array}{c}\text { Time } \\
\text { p-value }\end{array}$} & \multirow{2}{*}{$\begin{array}{c}\text { Group } \\
\text { p-value }\end{array}$} \\
\hline & Baseline & Follow-up & Baseline & Follow-up & Baseline & Follow-up & & & & \\
\hline 10mWT & \multicolumn{2}{|c|}{ Mean and SD } & \multicolumn{2}{|c|}{ Mean and SD } & \multicolumn{2}{|c|}{ Mean and SD } & & & & \\
\hline N. of steps & $16.4 \pm 2.6$ & $17.5 \pm 2.7$ & $17.7 \pm 2.8$ & $18.7 \pm 1.6$ & $16.2 \pm 2.6$ & $20.0 \pm 7.5$ & 0.147 & 0.391 & $0.001^{*}$ & 0.354 \\
\hline $\mathrm{GS}(\mathrm{m} / \mathrm{s})$ & $1.2 \pm 0.2$ & $1.1 \pm 0.2$ & $1.0 \pm 0.1$ & $1.0 \pm 0.0$ & $1.1 \pm 0.2^{+\#}$ & $0.9 \pm 0.2^{\#}$ & $0.019^{\star}$ & 0.727 & $<0.001^{*}$ & $0.044^{*}$ \\
\hline $\begin{array}{l}\text { Cadence } \\
\text { (steps/min) }\end{array}$ & $113.0 \pm 13.6$ & $113.2 \pm 11.8$ & $103.9 \pm 15.5$ & $108.8 \pm 7.9$ & $106.0 \pm 14.7$ & $102.4 \pm 13.1$ & 0.285 & 0.264 & 0.828 & 0.123 \\
\hline
\end{tabular}

FAB (maximum

score=18)

\begin{tabular}{lcccccccccc}
\hline Score & $11.0 \pm 3.5$ & $13.1 \pm 3.1$ & $8.7 \pm 2.6^{\#}$ & $10.1 \pm 3.1^{\#}$ & $7.2 \pm 2.7^{\#}$ & $9.5 \pm 5.2^{\#}$ & 0.745 & 0.094 & $0.003^{*}$ & $0.006^{*}$ \\
\hline $\begin{array}{l}\text { CDT (maximum } \\
\text { score }=10 \text { ) }\end{array}$ & & & & & & & & & & \\
\hline Score & $7.7 \pm 2.4$ & $7.2 \pm 3.0$ & $6.5 \pm 2.9$ & $6.6 \pm 3.4$ & $7.0 \pm 2.8$ & $5.0 \pm 3.7$ & 0.471 & 0.171 & 0.217 & 0.343 \\
\hline
\end{tabular}

M $\pm S D$ : mean \pm standard deviation; PrC: preserved cognition; MCl: mild cognitive impairment; AD: Alzheimer disease; GS: gait speed; 10mWT: 10-meter walk test; $n^{0}$ : number; FAB: Frontal Assessment Battery; CDT: clock-drawing test; $+p<0.05$ in comparison to PrC group at baseline; \#p<0.05 in comparison to PrC group; ${ }^{\star} p<0.05$; high score on FAB and CDT: high score on executive function. 
which reports a substantial change in GS associated with a reduction in cognitive performance after a 24-month follow-up.

In six-month follow-up studies of gait changes, ${ }^{34-36}$ no significant differences in GS were found in older adults with MCI. However, a 30-month follow-up study reports slower walking in older adults with amnestic $\mathrm{MCI},{ }^{15}$ which differs from the sample in the present investigation.

A slower GS was identified in older adults with MCI compared to those with $\operatorname{PrC}$ at baseline, but not at follow-up, possibly because GS in the $\operatorname{PrC}$ group has become slower over time, reflecting the influence of aging. ${ }^{33,37-40}$ It is believed that MCI participants have already reached a plateau in the GS decline. In addition, maybe changes on GS in the $\mathrm{MCI}$ group were not significant enough to be detected in a small sample size like this. Furthermore, possibly due to the heterogeneous evolution in the $\mathrm{MCI}$ group during follow-up, as some may have resumed normal cognition, remained stable or progressed to dementia. Although not confirmed by our data, studies suggest that the slowing of gait in individuals with $\operatorname{PrC}$ and mild DA is due to aging ${ }^{33}$ and cognitive impairment, ${ }^{13}$ respectively. The difficulty in assessing gait in older people is highlighted.

Although no significant difference was found among the groups, the $\mathrm{AD}$ group took the most number of steps on the $10 \mathrm{mWT}$. As the power of this test is low, a larger number of individuals in the sample could have resulted in a significant $\mathrm{p}$-value.

Regarding EF, no differences among groups or between times were found on the CDT and the change in FAB results over time was similar in all three groups.
Moreover, significant differences in relation to $\mathrm{FAB}$ were found between the $\operatorname{PrC}$ and $\mathrm{MCI}$ groups as well as between the $\operatorname{PrC}$ and mild $\mathrm{AD}$ groups at baseline, whose differences were maintained at follow-up. The change in FAB was an improvement in the EF for all groups. Therefore, the CDT and FAB do not seem to be good markers to differentiate the evolution of cognition in these groups.

The FAB has discriminant validity as well as good internal consistency, interobserver reliability and convergent validity. ${ }^{25}$ However, there are no Minimum Detectable Change analyses to determine whether the change in score was clinically relevant. The standard deviations of the three groups ranged from 2.6 to 5.2 points and were reasonably high in the follow-up period compared to the values reported in other studies. ${ }^{41,42}$ Studies with larger samples may facilitate the conclusion of the findings.

In addition, the increase in the FAB was believed to have occurred for four reasons:

- It was a group with mild $\mathrm{AD}$, which mainly affects the temporal lobes.

- It was $A D$ rather than another form of dementia that affects the frontal lobe more.

- The introduction of new pharmacological treatments (37.5\%), physical activity (65\%), and physical therapy interventions $(57.5 \%)$ among the participants during the period between evaluations, given that some received their diagnosis during the study.

- Due to possible learning of the instruments, since improvements were found in all groups (with no difference among groups).

Table 3. Correlation between change in Frontal Assessment Battery and clock-drawing test tests and change in gait speed among older adults with preserved cognition, mild cognitive impairment, and mild Alzheimer disease.

\begin{tabular}{|c|c|c|c|}
\hline Correlation measurements & $\begin{array}{c}\text { PrC group } \\
(n=19)\end{array}$ & $\begin{array}{l}\text { MCI group } \\
\quad(n=15)\end{array}$ & $\begin{array}{c}\text { AD group } \\
(n=6)\end{array}$ \\
\hline DFAB with DGS & $p=0.146$ & $p=0.108$ & $\mathrm{p}=0.851$ \\
\hline DFAB with DSTEPS & $\mathrm{p}=0.730$ & $p=0.129$ & $\begin{array}{c}\mathbf{p}=\mathbf{0 . 0 0 1} \\
\mathrm{r}=-0.978\end{array}$ \\
\hline DFAB with DCADENCE & $\begin{array}{l}\mathbf{p}=\mathbf{0 . 0 4 2} \\
\mathrm{r}=0.472\end{array}$ & $\mathrm{p}=0.627$ & $\mathrm{p}=0.664$ \\
\hline DCDT with DGS & $\mathrm{p}=0.819$ & $\mathrm{p}=0.635$ & $\mathrm{p}=0.747$ \\
\hline DCDT with DSTEPS & $p=0.696$ & $p=0.434$ & $p=0.119$ \\
\hline DCDT with DCADENCE & $\mathrm{p}=0.569$ & $\mathrm{p}=0.104$ & $\mathrm{p}=0.968$ \\
\hline
\end{tabular}

PrC: preserved cognition; MCl: mild cognitive impairment; AD: Alzheimer disease; FAB: Frontal Assessment Battery; CDT: clock-drawing test; GS: gait speed; $\Delta$ : final value-initial value; r: correlation coefficient. 
In studies by Ansai et al., ${ }^{43}$ changes in EF were found at baseline and gait alterations were found at follow-up. However, changes in EF and GS do not go hand in hand, since motor decline precedes that of EF. GS is a good early marker of the development of MCI. ${ }^{15,16}$

No significant association was found between changes in the FAB and GS. However, associations were found between changes in the FAB and both the number of steps in the mild $A D$ group and cadence in the $\operatorname{PrC}$ group. These findings are in agreement with the data reported by Pedroso et al..$^{44}$ and Melo et al., ${ }^{45}$ respectively. At follow-up, a decline in GS was found, while EF remained stable. Taylor et al. ${ }^{22}$ found an association between baseline GS and decline in EF in a 12-month period among older adults with dementia. In contrast, the present study included MCI and mild AD. Coelho et al. ${ }^{6}$ also found an association between GS and EF, but in a heterogeneous sample that included individuals with both mild and moderate AD. As these groups differ significantly in terms of cognitive and motor impairment, ${ }^{6-8}$ it is necessary to study them separately.

Two studies found an association between changes in gait and $\mathrm{EF},{ }^{12,46}$ however, the divergent results of the present investigation may have occurred because the authors used instruments to assess EF and gait variables different from those used in this study investigation. The literature shows that in addition to the consistency in the results and quality of the studies, there seems to be variations in the results according to the instrument chosen for the evaluation, sample size, population studied, and the evolution of cognitive impairment in the volunteers. ${ }^{12,22,46,47}$

As MCI and dementia become more prevalent with the increase in age, early diagnosis is essential. The results of the present study seem to indicate that slowing GS is a potential early marker of cognitive decline. Thus, rehabilitation professionals should perform periodic assessments of GS in older adults. Once decreased GS over time is detected, such individuals should be screened for cognitive decline to obtain an early diagnosis and timely intervention. Therefore, rehabilitation professionals should prioritize attention to gait variables during the clinical care of older adults with the aim of preventing their decline. If older adults with slower gait are admitted to a rehabilitation clinic, the main intervention of the care should be to promote an increase in GS.

A limitation of the present study was the use of a convenience sample. However, the diagnostic criteria were rigorous and based on the current literature. ${ }^{17,21}$ Moreover, the stringent, sophisticated methodology, extensive evaluation, and use of clinical instruments widely employed in the clinical practice strengthened the study. Another limitation was the small number of volunteers who participated in the follow-up evaluation. Longitudinal studies with this type of population pose a challenge, since the older adults with $\mathrm{MCI}$ and $\mathrm{AD}$ can exhibit physical and cognitive frailty, which makes data collection more difficult. In addition, caregivers are often over-burdened and may have little time and/or interest in participating in studies. However, the small sample size may have some impact on the lack of significance in some results.

Future researches should carry out population-based studies in developing countries, which have socioeconomic inequalities and different health conditions, in order to offer greater reliability in the characterization of cognitive and motor impairment in these populations. It is fundamental to perform selective sampling that differentiates older adults with preserved cognition, those with subjective memory complaints, those with $\mathrm{MCI}$ and its subtypes and those with $\mathrm{AD}$ and its different phases. It is also important to standardize the use of other common evaluation instruments of gait and/or EF to compare cognitive profiles, such as the Timed up and Go test. Finally, it is necessary to reproduce these analyses in larger samples so that loss to follow-up does not interfere with the results.

As conclusion, gait of older adults with $\operatorname{PrC}$ and mild AD slowed down in 32 months and, over the years, this group needs to take more steps to cover the same distance. The same period was insufficient to detect deficits in $\mathrm{EF}$ in the $\mathrm{PrC}, \mathrm{MCI}$, and $\mathrm{AD}$ groups, suggesting that gait changes occur in older adults before EF are affected. This study contributes to the field of research in older adults with cognitive impairment and offers a theoretical foundation for the planning of interventions and health promotion strategies for this population.

\section{ACKNOWLEDGMENTS}

This study was supported by the Fundação de Amparo à Pesquisa do Estado de São Paulo (FAPESP).

Authors' contributions. NOCC: conceptualization, data curation, formal analysis, funding acquisition, investigation, visualization, writing - original draft, review \& editing. JHA: conceptualization, formal analysis, investigation, methodology, supervision, writing - review \& editing. LPA: formal analysis, investigation, project administration, supervision, writing - review \& editing. MPBO, DCPS, FACV, ACMT: investigation, writing - review \& editing. 


\section{REFERENCES}

1. Cummings JL, Cole G. Alzheimer disease. JAMA. 2002;287(18):2335-8. https://doi.org/10.1001/jama.287.18.2335

2. Yaari R, Corey-Bloom J. Alzheimer's disease. Semin Neurol. 2007;27(1):3241. https://doi.org/10.1055/s-2006-956753

3. Batum K, Çinar N, Şahın Ş, Çakmak MA, Karşidağ S. The connection between $\mathrm{MCl}$ and Alzheimer disease: neurocognitive clues. Turkish J Med Sci. 2015;45(5):1137-40. https://doi.org/10.3906/sag-1404-179

4. Chan RC, Shum D, Toulopoulou T, Chen EY. Assessment of executive functions: Review of instruments and identification of critical issues. Arch Clin Neuropsychol. 2008;23(2):201-16. https://doi.org/10.1016/j.acn.2007.08.010

5. Harrison J, Rentz DM, McLaughlin T, Niecko T, Gregg KM, Black RS, et al. Cognition in $\mathrm{MCl}$ and Alzheimer's disease: Baseline data from a longitudinal study of the NTB. Clin Neuropsychol. 2014;28(2):252-68. https://doi.org/ 10.1080/13854046.2013.875595

6. Coelho FG, Stella F, Andrade LP, Barbieri FA, Santos-Galduróz RF, Gobbi $\mathrm{S}$, et al. Gait and risk of falls associated with frontal cognitive functions at different stages of Alzheimer's disease. Neuropsychol Dev Cogn B Aging Neuropsychol Cogn. 2012;19(5):644-56. https://doi.org/10.1080/13825 585.2012 .661398

7. Zidan M, ArCoverde C, Araújo NB, Vasques P, Rios A, Laks J, et al. Motor and functional changes in different stages of Alzheimer's disease. Rev Psiquiatr Clín. 2012;39(5):161-5. https://doi.org/10.1590/S010160832012000500003

8. Ferreira L, Cochito T, Caíres F, Marcondes L, Saad P. Capacidade funcional de idosos institucionalizados com e sem doença de Alzheimer. Rev Bras Geriatr Gerontol. 2014;17(3):567-73. https://doi.org/10.1590/18099823.2014.13102

9. McGough EL, Cochrane BB, Pike KC, Logsdon RG, McCurry SM, Teri $\mathrm{L}$. Dimensions of physical frailty and cognitive function in older adults with amnestic mild cognitive impairment. Ann Phys Rehabil Med. 2013;56(5):32941. https://doi.org/10.1016/..rehab.2013.02.005

10. Persad CC, Jones JL, Ashton-Miller J, Alexander NB, Giordani B. Executive function and gait in older adults with cognitive impairment. $J$ Gerontol A Biol Sci Med Sci. 2008;63(12):1350-5. https://doi.org/10.1093/ gerona/63.12.1350

11. Boripuntakul $S$, Sungkarat $S$. Specific but not global cognitive functions are associated with gait initiation in older adults. J Aging Phys Act. 2017;25(1):128-33. https://doi.org/10.1123/japa.2015-0228

12. Savica R, Wennberg AMV, Hagen C, Edwards K, Roberts RO, Hollman $\mathrm{JH}$, et al. Comparison of gait parameters for predicting cognitive decline: The Mayo Clinic Study of Aging. J Alzheimer's Dis. 2017;55(2):559-67. https://doi.org/10.3233/JAD-160697

13. Beauchet $\mathrm{O}$, Annweiler C, Callisaya ML, De Cock AM, Helbostad JL, Kressig RW, et al. Poor gait performance and prediction of dementia: results from a meta-analysis. J Am Med Dir Assoc. 2016;17(6):482-90. https://doi.org/10.1016/j.jamda.2015.12.092

14. Aggarwal NT, Wilson RS, Beck TL, Bienias JL, Bennett DA. Motor dysfunction in mild cognitive impairment and the risk of incident Alzheimer disease. Arch Neurol. 2006;63(12):1763-9. https://doi.org/10.1001/ archneur.63.12.1763

15. Dodge HH, Mattek NC, Austin D, Hayes TL, Kaye JA. In-home walking speeds and variability trajectories associated with mild cognitive impairment. Neurology. 2012;78(24):1946-52. https://doi.org/10.1212/ WNL.0b013e318259e1de

16. Gillain S, Dramé M, Lekeu F, Wojtasik V, Ricour C, Croisier JL, et al. Gait speed or gait variability, which one to use as a marker of risk to develop Alzheimer disease? A pilot study. Aging Clin Exp Res. 2016;28(2):249-55. https://doi.org/10.1007/s40520-015-0392-6

17. McKhann GM, Knopman DS, Chertkow H, Hyman BT, Jack CR, Kawas $\mathrm{CH}$, et al. The diagnosis of dementia due to Alzheimer's disease: recommendations from the National Institute on Aging-Alzheimer's Association workgroups on diagnostic guidelines for Alzheimer's disease. Alzheimer's Dement. 2011;7(3):263-9. https://doi.org/10.1016/j.jalz.2011.03.005

18. Montaño MB, Ramos LR. Validity of the Portuguese version of Clinical Dementia Rating. Rev Saude Publica. 2005;39(6):912-7. https://doi. org/10.1590/S0034-89102005000600007

19. Brucki SMD, Nitrin R, Caramelli P, Bertolucci PHF, Okamoto IH. Sugestões para o uso do Mini-Exame do Estado Mental no Brasil. Arq Neuro-Psiquiatr. 2003;61(3B):777-81. https://doi.org/10.1590/S0004282X2003000500014

20. Pfeffer Rl, Kurosaki T, Harrah $\mathrm{CH}$, Chance JM, Filos S. Measurement of functional activities in older adults in the community. J Gerontol. 1982;37(3):323-9. https://doi.org/10.1093/geronj/37.3.323

21. Petersen RC. Mild cognitive impairment as a diagnostic entity. Arch Neurol. 2004;256(3):183-94. https://doi.org/10.1111/j.1365-2796.2004.01388.x
22. Taylor ME, Lasschuit DA, Lord SR, Delbaere K, Kurrle SE, Mikolaizak AS, et al. Slow gait speed is associated with executive function decline in older people with mild to moderate dementia: a one year longitudinal study. Arch Gerontol Geriatr. 2017;73:148-53. https://doi.org/10.1016/j. archger.2017.07.023

23. Ojagbemi A, D'Este C, Verdes E, Chatterii S, Gureje O. Gait speed and cognitive decline over 2 years in the lbadan study of aging. Gait Posture. 2015;41(2):736-40. https://doi.org/10.1016/j.gaitpost.2015.01.011

24. Castelo MS, Coelho-Filho JM, Carvalho AF, Lima JWO, Noleto JCS, Ribeiro $\mathrm{KG}$, et al. Validity of the Brazilian version of the Geriatric Depression Scale (GDS) among primary care patients. Int Psychogeriatrics. 2010;22(1):10913. https://doi.org/10.1017/S1041610209991219

25. Dubois B, Slachevsky A, Litvan I, Pillon B. The FAB: A frontal assessment battery at bedside. Neurology. 2000;55(11):1621-6. https://doi. org/10.1212MNL.55.11.1621

26. Beato RG, Nitrini R, Formigoni AP, Caramelli P. Brazilian version of the Frontal Assessment Battery (FAB): preliminary data on administration to healthy elderly. Dement Neuropsychol. 2007;1(1):59-65. https://doi. org/10.1590/s1980-57642008dn10100010

27. Sunderland T, Hill JL, Mellow AM, Lawlor BA, Gundersheimer J, Newhouse PA, et al. Clock drawing in Alzheimer's disease: a novel measure of dementia severity. J Am Geriatr Soc. 1989;37(8):725-9. https://doi. org/10.1111/j.1532-5415.1989.tb02233.x

28. Atalia-Silva KC, Lourenço RA. Tradução, adaptação e validação de construto do Teste do Relógio aplicado entre idosos no Brasil. Rev Saúde Pública. 2008:42(5):930-7. https://doi.org/10.1590/S003489102008000500020

29. Shulman KI. Clock-drawing: Is it the ideal cognitive screening test? Int J Geriatr Psychiatry. 2000;15(6):548-61. https://doi.org/10.1002/ 1099-1166(200006)15:6<548::AID-GPS242>3.0.CO;2-U

30. Novaes RD, Miranda AS, Dourado VZ. Usual gait speed assessment in middle-aged and elderly Brazilian subjects. Rev Bras Fisioter. 2011;15(2):117-22. https://doi.org/10.1590/S1413-35552011000200006

31. Pinheiro MB, Scianni AA, Ada L, Faria CD, Teixeira-Salmela LF. Reference values and psychometric properties of the lower extremity motor coordination test. Arch Phys Med Rehabil. 2014;95(8):1490-7. https://doi. org/10.1016/i.apmr.2014.03.006

32. Braun T, Thiel C, Schulz RJ, Grüneberg C. Reliability of mobility measures in older medical patients with cognitive impairment. BMC Geriatr. 2019;19(1):20. https://doi.org/10.1186/s12877-019-1036-z

33. Studenski S, Perera S, Patel K, Rosano C, Faulkner K, Inzitari M, et al. Gait speed and survival in older adults. J Am Med Assoc. 2011;305(1):50-8. https://doi.org/10.1001/jama.2010.1923

34. Doi T, Makizako H, Shimada H, Yoshida D, Tsutsumimoto K, Sawa R, et al. Effects of multicomponent exercise on spatial-temporal gait parameters among the elderly with amnestic mild cognitive impairment (aMCl): Preliminary results from a randomized controlled trial (RCT). Arch Gerontol Geriatr. 2013:56(1):104-8. https://doi.org/10.1016/i.archger.2012.09.003

35. Makizako H, Doi T, Shimada H, Yoshida D, Tsutsumimoto K, Uemura $\mathrm{K}$, et al. Does a multicomponent exercise program improve dual-task performance in amnestic mild cognitive impairment? A randomized controlled trial. Aging Clin Exp Res. 2012;24(6):640-6. https://doi. org $/ 10.3275 / 8760$

36. Varela S, Ayán C, Cancela JM, Martín V. Effects of two different intensities of aerobic exercise on elderly people with mild cognitive impairment: A randomized pilot study. Clin Rehabil. 2012;26(5):442-50. https://doi. org/10.1177/0269215511425835

37. Layman AJ, Li C, Simonsick E, Ferrucci L, Carey JP, Agrawal Y. Association between saccular function and gait speed: data from the Baltimore Longitudinal Study of Aging. Otol Neurotol. 2015;36(2):260-6. https://doi. org/10.1097/MAO.0000000000000544

38. Schrager MA, Kelly VE, Price R, Ferrucci L, Shumway-Cook A. The effects of age on medio-lateral stability during normal and narrow base walking. Gait Posture. 2008;28(3):466-71. https://doi.org/10.1016/j. gaitpost.2008.02.009

39. Tolea MI, Costa PT, Terracciano A, Griswold M, Simonsick EM, Najjar SS, et al. Sex-specific correlates of walking speed in a wide age-ranged population. Journals Gerontol - Ser B Psychol Sci Soc Sci. 2010;65B(2):174-84. https://doi.org/10.1093/geronb/gbp130

40. Ko SU, Hausdorff JM, Ferrucci L. Age-associated differences in the gait pattern changes of older adults during fast-speed and fatigue conditions: Results from the Baltimore longitudinal study of ageing. Age Ageing. 2010;39(6):688-94. https://doi.org/10.1093/ageing/afq113

41. De Paula JJ, Malloy-Diniz LF. Executive functions as predictors of functional performance in mild Alzheimer's dementia and mild cognitive impairment elderly. Estud Psicol (Natal). 2013;18(1):117-24. https://doi.org/10.1590/ S1413-294X2013000100019 
42. De Paula JJ, Moreira L, Nicolato $R$, de Marco LA, Côrrea H, Romano-Silva $M A$, et al. The tower of London test: Different scoring criteria for diagnosing Alzheimer's disease and mild cognitive impairment. Psychol Rep. 2012;110(2):477-88. https://doi.org/10.2466/03.10.13.PR0.110.2.477-488

43. Ansai JH, Andrade LP, Nakagawa TH, Vale FAC, Caetano MJD, Lord SR, et al. Cognitive correlates of timed up and go subtasks in older people with preserved cognition, mild cognitive impairment, and Alzheimer's disease. Am J Phys Med Rehabil. 2017;96(10):700-5. https://doi.org/10.1097/ PHM.0000000000000722

44. Pedroso RV, Corazza DI, Andreatto CA de A, da Silva TMV, Costa JLR, Santos-Galduróz RF. Cognitive, functional and physical activity impairment in elderly with Alzheimer's disease. Dement Neuropsychol. 2018;12(1):2834. https://doi.org/10.1590/1980-57642018dn12-010004
45. Melo LM, Ansai JH, Rossi PG Vale FAC, Takahashi AC de M Andrade LP de. Performance of an adapted version of the Timed Up-and-Go Test in people with cognitive impairments. J Mot Behav. 2019;51(6):647-54. https://doi.org/10.1080/00222895.2018.1552 917

46. Knapstad MK, Steihaug OM, Aaslund MK, Nakling A, Naterstad IF, Fladby $\mathrm{T}$, et al. Reduced walking speed in subjective and mild cognitive impairment. J Geriatr Phys Ther. 2017;42(3):E122-8. https://doi.org/10.1519/ JPT.0000000000000157

47. Peel NM, Alapatt LJ, AStat LVJ, Hubbard RE. The association between gait speed and cognitive status in community-dwelling older people: a systematic review and meta-analysis. J Gerontol A Biol Sci Med Sci. 2019;74(6):943-8. https://doi.org/10.1093/gerona/gly140 